\title{
Staging Othello: Turning students into directors
}

\author{
Alyse Knorr* \\ $2 / 3 / 2020^{\dagger}$
}

\begin{abstract}
The Othello staging project invites introductory literature students to imagine that they are directing a new production of Othello. Students create a production proposal and poster that illustrate their directorial choices, using their original interpretation of the play as a guiding philosophy. This assignment successfully addresses many of the challenges associated with teaching an introductory-level, required "core" course of non-English-majors, as well as the challenges of teaching drama in general and Shakespeare in particular. Creative response assignments like this prompt can foster student engagement, mitigate student writing anxiety, and deepen student understandings of plays as living documents open to artistic interpretation.
\end{abstract}

Teaching drama in an introductory literature course offers a unique set of challenges, mainly since plays are meant to be seen, not read (Brown, 2000; Dulaney, 2012). However, the cost of attending local theater performances can be prohibitive for many students, and students can find it difficult to get excited about reading lines or blocking out scenes in class. Teaching Shakespeare can also be challenging, as many students still associate Shakespeare with high school and can be put off by language they see as antiquated (Dulaney, 2012; Haughey, 2012; Shoemaker, 2013), or can struggle to connect the themes of a 400-year-old play to their own lives.

The Othello staging assignment aims to address these challenges by immersing students in a creative exercise that requires a rigorous close reading of the text. The assignment prompt asks students to imagine themselves as the director of a film or stage (their choice) production of Othello. Students then write a production proposal that outlines and explains their choices about setting, set design, mood, casting, costumes, music, and script revisions, using their original interpretation of the play to guide those choices. Students also create a movie or play poster that visually demonstrates their interpretation. The

\footnotetext{
${ }^{*}$ Regis University, aknorr@regis.edu. Copyright 2020 Alyse Knorr. This work is licensed under a Creative Commons Attribution-NonCommercial 4.0 International License (http://creativecommons.org/licenses/by-nc/4.0/).

${ }^{\dagger}$ Submitted, 7/24/2018; Accepted, 9/16/2019.
} 
purpose of this poster is to deepen students' understanding of their own interpretations by asking them to represent them concisely and visually. Because plays and films are visual media, I want to challenge my students to think visually for this assignment; the posters also serve as a useful way to generate and focus conversation when students present their proposals to their classmates.

The learning outcomes for this assignment are for students to:

1. Formulate a clear, complex, and original interpretation of the play grounded in textual evidence and demonstrated through their directorial choices;

2. Articulate, through this interpretation, Othello's relevance to contemporary audiences;

3. Develop an understanding of plays as living documents, open to interpretation by the directors, actors, and production crews who stage them;

4. Cultivate a deeper appreciation for Shakespeare in general, and Othello in particular.

\section{Assignment Design and Rationale}

I designed the Othello staging assignment for use in an introductory literature course for non-English-majors, required in the core curriculum for all undergraduate students at my home institution, Regis University. The most typical challenges in teaching a course like this one are fostering student engagement with the course material and mitigating student anxieties. Because students do not choose to enroll in this class, they may not be interested in the subject matter and may even resent the fact that they must take yet another English class. Many students also bring with them baggage from past English classes, including a lack of confidence about their writing or literary analysis skills, or a feeling of dread about having to read more "boring" or difficult "classic" literature.

In order to address these challenges, and given the significant research on the benefits of creative assignments, I typically include at least one creative project in my introductory literature courses. Students often find creative assignments more interesting and more approachable than traditional written essays (Grace, 1991), and creative assignments have been found to yield higher rates of student success and satisfaction (McGlinn \& McGlinn, 2003). Despite the long-standing assumption in higher education that critical analysis - as opposed to creative response - is the "proper response" to literary texts (Wilson, 2011, p. 439), literature students can significantly benefit from the inclusion of creative assignments alongside critical analysis assignments (Duke, 1980; Wilson, 2011), particularly when studying Shakespeare. The staging prompt exists within a long history of teaching Shakespeare using nontraditional approaches (Desmet, 2009; Dulaney, 2012; Erickson \& Hunt, 2005; Shoemaker, 2013), especially through a performance lens (Haughey, 2012). My assignment extends this tradition by putting students in the director role rather than the role of a performer and by asking students to create a visual representation of their interpretation, via a poster, along with their written proposals. 
The staging assignment also provides opportunities to incorporate interactive teaching methods and film adaptations into the classroom, which have been found to generate the highest levels of student comprehension and interest in Shakespeare texts (Shoemaker, 2013). In this regard, the wealth of Shakespeare adaptations available on YouTube, DVD, and streaming services prove decidedly useful in the classroom (Desmet, 2009), especially considering that "[v]iewing and comparing two performances of the identical playtext is another way to explore the performative aspects of a drama" (Brown, 2000, p. 12). Such an exercise allows students to "consider alternative enactments, weighing a choice between different emphases" (Brown, 2000, p. 5). Taking this idea one step further, Brown encourages instructors to help their students imaginatively "position themselves as the director" (p. 5) while they read a work of drama.

Following Brown's (2000) advice, I developed the Othello staging assignment as a way to help my students deepen their understanding and appreciation of Othello. The production proposal, sometimes known as a "theater proposal," is an authentic genre used by directors and/or writers to pitch their plays to producers, theater companies, or arts councils. The specific requirements of a production proposal vary depending on the audience to whom the artist is submitting, but typically include a rationale, set design specifications, and details about the casting and interpretative choices.

As a course assignment, the production proposal invites students to read closely in order to develop their own interpretation of Othello and defend their directorial choices. It encourages students to think of the play as a living document, open to wide interpretation and meant more to be staged and viewed than read. It also shows them how much variety can exist in different approaches to a play - how one production might choose to highlight a certain theme or conflict over another, or how directorial choices can serve to reimagine character motivations. Indeed, the most challenging aspect of this assignment is for students to explain their directorial choices using their interpretations as a basis. For instance, when I push a student to articulate why they have chosen to cast Idris Elba as Othello in their film, and what this casting choice reveals about their interpretation, they are often forced to return to the text and deepen their own understanding of the play in order to identify an answer.

\section{In-Class Scaffolding Activities}

I usually save this unit for the end of the semester and spend about a month on the play and the staging assignment. Leading up to this final month of the semester, my students have read short stories, novels, and poetry, and have written traditional literary analysis papers and researched arguments. They have therefore gained experience analyzing and writing about literature at the college level, and the course culminates in a creative application of their analysis skills.

As we read the play together over the course of several weeks, I screen clips from several different film and stage versions of Othello, including the Oliver Parker film starring Kenneth Branagh (Barron, 1995), the modern-day teenage basketball drama $O$ (Fried 
\& Gitter, 2001), a traditional stage version at the Globe Theatre (Milam, 2007), and a National Theatre stage version set in the current war in Afghanistan (Hytner, 2013). Whenever possible, I strive to show clips of different versions of the same scene. Students then discuss which interpretations they found most entertaining, most effective, and/or most true to the original text. Students usually have very strong opinions that later guide their own directorial choices, and they often refer to the clips from class in their production proposals as sources of inspiration.

Throughout these classroom discussions, which are sometimes scaffolded by freewrites, I strive to help students understand the differences between stage versions and film versions of the play, so that students can grasp the unique opportunities and challenges of each medium. Because many of the students in my class have never seen a live theater production of any kind, I must be careful to note that even though we are watching videos of stage performances, the stage itself is the medium, not film. I ask my students what differences they perceive between the film versions and stage versions of the play, such as the volume of the actors' voices or the ability of the camera to zoom in on particular items and faces. I also ask my students to consider which medium appeals to them more for their own interpretation and why.

We also discuss unethical or problematic directorial choices, such as blackface. Using videos and podcasts (see specific suggestions in Supplemental Materials), my students learn about the history of blackface and articulate why this tradition is so deeply problematic. We also discuss what modern-day blackface looks like, using examples from pop culture such as the 2016 Bob Marley Snapchat filter, or from the news, such as the scandal around Virginia governor Ralph Northam's college yearbook blackface photos. In this way, the assignment falls in line with my institution's Jesuit values of social justice and standing with the marginalized and oppressed.

I also show a PowerPoint of various Othello movie and theater posters, asking students to write down what word they associate with each. A conversation ensues about how any given production of the play might focus more closely on one of the text's themes than on others, and how posters can reveal that focus along with the overall tone of the production. I often ask students which poster seems closest to their own interpretation of the play and why. I then introduce them to Canva and Piktochart, both free, easy-to-use web platforms for creating posters, and encourage them to start thinking about how to visually represent their own interpretation of the play (see Supplemental Materials for examples).

In order to show my students the roles that directors and actors play in interpreting the text, I pair them in class and have them perform a scene between Othello and Desdemona with one another (not in front of the whole class) multiple times. Each time, I assign the two actors a different emotion to play, such as shock, frustration, fear, etc. Students then discuss the effects of these alternate portrayals, and how they may or may not be justified by the text. I then lead my students in some free-writing exercises connecting this activity to their own interpretation. 
I help students work through a guided handout (outlined in the Supplemental Materials) that helps them break the assignment down into its component steps. The week before the final proposal and poster are due, students bring a draft of each to class and peer review them to get feedback and new ideas.

Students share the final results of their staging projects during a gallery walk in which we hang up the posters and take a tour through them all, with each student director giving a brief, informal and unrehearsed pitch about their production and taking questions from the audience. This culminating exercise is central to the success of the assignment overall, as it is during this exercise that students see the tremendous variety in their own community's interpretations of the same text.

\section{Student Responses and Benefits}

I have been consistently impressed by the thoughtful interpretations and literary analyses revealed in my students' production proposals. Students demonstrate a meaningful understanding of the play-informed primarily by in-class discussions and their individual interpretations - through their careful choices about dialogue, music selection, cutting scenes, reordering scenes, rewriting scenes, blocking, and advising actors on how to play their characters. Some students who had previously seemed resistant to Shakespeare's archaic language provided nuanced defenses for why they would retain that language in their contemporary production. Other students, who preferred to update the archaic language in their productions, provided brilliant adaptions of certain scenes that demonstrated not only a rich comprehension of what the original text meant but also a clear appreciation for the play's relevance in today's society.

The wealth of creativity in the responses is also staggering. I have seen students reimagine Othello as a telenovela, as a romance, and as a science fiction film - and the more out-of-the-box the interpretation, the stronger the students' justifications for their interpretations. One student set her play in the 1950s, emphasizing anti-miscegenation laws and racial segregation. Another chose to highlight the homoerotic tensions in the play by having Iago be in love with Othello. Another student focused on the portrayal of mental illness as a theme by setting it in a mental institution, noting that her production highlights the ways that Othello's mental illness "prevents him from having control over the voices in his head" and allows him to be easily manipulated. (See Supplemental Materials for these students' posters.) One student even imagined a sequel to Othello that would be set today in the context of Black Lives Matter and \#MeToo.

Perhaps the most fascinating response I saw to this assignment was a student who took an intersectional feminist approach to the play by setting it in a modern-day office and recasting Othello as a black woman and high-ranking CEO of the company. Iago, a white man, is a jealous executive just below her on the corporate ladder. "[S]eeing the monstrous dynamic of racism combined with sexism can be very illuminating," this student wrote; "It will show how both women and people of color (particularly women of color) in positions are treated. It will show the struggles required of them to earn 
their place in society, while still showing that this rise in the rank is undermined at every point."

While the high level of analysis in student work demonstrates a rich understanding of Shakespeare's Othello and its themes, there are strategies to further improve the assignment. For instance, one drawback of this assignment is that some students do not tie their analyses to direct quotes from the text but rather from paraphrases and summaries of the text. The next time I teach this assignment, I plan to explicitly require quotes from the text as supporting evidence, which will make the assignment even more rigorous. In future iterations of this assignment, I would also like to have students work together as a class to stage or film one scene, with students working in individual roles as directors, actors, costumers, producers, set designers, publicity coordinators, prop masters, etc. This would allow students to approximate the "real-life" experience of collaborative creativity involved in filming or staging a play by working as a production team.

\section{Conclusion}

I have found this assignment to be successful at meeting all of the stated learning outcomes. Student work demonstrates a deep understanding of the play and a meaningful appreciation for plays as living works of art with significant contemporary relevance. An additional advantage of this assignment is that it is easily adaptable for any play. And although it works especially well in an introductory level course for non-majors, it would also be appropriate for English major courses and/or theater courses.

In addition, this assignment mitigates many of the challenges associated with teaching drama, and Shakespeare in particular. The assignment feels lower- stakes to students who lack confidence in their writing and literary analysis skills, but is still as intellectually rigorous as a traditional paper, as evidenced in Anderson et al. (2001)'s revision of Bloom's Taxonomy of Educational Objectives, which places "creating" at the top of the scheme. The assignment also provides an avenue of expression for students with more creative skillsets and students with learning disabilities (Chickering \& Gamson, 1987) and helps students develop the creative problem-solving skills they will need in the workplace (Reynolds, Stevens, \& West, 2013). Finally, the staging exercise feels more engaging to resistant students who find literature "boring." In line with research indicating that creative assignments stimulate student motivation (McGlinn \& McGlinn, 2003), the Othello staging assignment seems to generate an authentic sense of enthusiasm about literature in students and an interest in reading or attending more plays.

Indeed, in general, my students typically submit final production proposals with word counts far exceeding the 1,000 required. Although brevity would be more valuable in the real-world version of this genre, I allow students to exceed the minimum word count and do not set a maximum limit because I want to encourage them to get excited about Shakespeare and get detailed in their proposals. In fact, many students also submit supplemental, unrequired materials for this assignment, such as photographs of shooting 
locations, stage design sketches, or headshots of the actors they would cast. This wealth of additional, unrequired information demonstrates for me the enthusiasm that students have for this project. It is my hope that they will carry this enthusiasm for literature with them for the rest of their college careers and beyond.

\section{Assignment: Othello Staging}

(To view a PDF facsimile of the original formatting of this assignment, return to this article's homepage and locate the link to the "Assignment" PDF.)

Paper Length: at least 1,000 words, and no more than 1,500

MLA format

As we've discussed in class, the written words of a play only comprise part of the art form. The rest is in the acting, costumes, stage design, and, especially, the direction of a particular production. For this assignment, instead of showing your interpretation of Othello through a scholarly analysis, you will show it through your directorial choices.

Pretend you are the director of a film or play version of Othello (you decide which). Write a production proposal that provides the following information (and any others you'd like to add):

- Introduction: Begin your proposal with a few sentences explaining what will be unique about your production. What will you focus on in your production? What is the central idea behind your interpretation of the play - the interpretation you will communicate to the audience in your directorial choices?

- Medium: Explain why you chose to direct a film adaptation or a stage version of the play. As we've discussed in class, film and theater offer unique challenges and affordances, as they are very different media. How will you make use of the affordances of your medium?

- Setting (time and place): Is your rendition set in today's world, or Shakespeare's, or 3,000 years into the future? Is it set in Venice, Brooklyn, or Mars?

- Setting (set design): If film, where would you shoot? If a play, how would you set the stage? Are we indoors? Outdoors? What do the shoot locations and sets look like for each scene?

- Mood: Grim and dark? Light-hearted and comical? Romantic and sweeping? Mysterious and dangerous? Etc.

- Actors: Which actors would you cast for each role?

- Costumes: How would you costume each of the characters?

- Music: When would you use music in your production, and what kinds of songs? 
- Language: Would you retain Shakespeare's original language, or update it for a modern audience?

- Scenes: Are there any scenes you would cut? Would you rearrange the order of any scenes?

- Scene focus: Choose any one scene and walk us through the choices you would make and direction you would give the actor. If film, when would you use close-ups? If theater, where on the stage would you have the actor walk? Is the actor speaking to the audience, to him/herself, or to someone else? How are the actors speaking to each other? Are they touching?

- Other: Are there any other changes you'd make from Shakespeare's original? Anything else you'd particularly highlight that I haven't asked about on this sheet?

Please explain WHY you've made each of your choices - how they tie together into your overall thematic focus. Finally, make sure to give your proposal a title that shows what your overall interpretation of the play is.

In addition to your proposal, I ask that you design a movie or play poster that sets the tone for your particular interpretation of the play. $\left(27^{\prime \prime} \mathrm{x} 40^{\prime \prime}\right.$ poster as a PDF or JPG file).

\section{References}

Anderson, L., Krathwohl, D., Airasian, P., Cruikshank, K., Mayer, R., Pintrich, P., ... Wittrock, M. (2001). A taxonomy for learning, teaching, and assessing: A revision of Bloom's taxonomy of educational objectives. New York: Longman.

Barron, D. (1995). Othello. Castle Rock Entertainment.

Brown, J. (2000). Teaching drama: Text and performance. Presented at the The Annual Meeting of the National Council of Teachers of English, Milwaukee, WI.

Chickering, A. W., \& Gamson, Z. F. (1987). Seven principles for good practice in undergraduate education. AAHE Bulletin, 39(7), 3-7.

Desmet, C. (2009). Teaching Shakespeare with YouTube. English Journal, 99(1), 65-70.

Duke, C. (1980). Encouraging student response to literature. In. Presented at the The Southeast National Council of Teachers of English Affiliate Conference, Atlanta, GA.

Dulaney, M. A. (2012). Using a prop box to create emotional memory and creative play for teaching Shakespeare's Othello. English Journal, 102(2), 37-43. Retrieved from http://www2.ncte.org/resources/journals/english-journal/

Erickson, P., \& Hunt, M. (2005). Approaches to teaching Shakespeare's Othello. New York, NY: Modern Language Association of America. 
Fried, D., \& Gitter, E. (2001). O. Daniel Fried Productions, Chickie the Cop, \& Dimension Films.

Grace, N. (1991). What our students like to write and why: Exploring the creative and the personal. In. Presented at the The Annual Meeting of the Conference on College Composition and Communication, Boston, MA.

Haughey, J. (2012). " What's Past Is Prologue":" English Journal" Roots of a PerformanceBased Approach to Teaching Shakespeare. English Journal, 101 (3), 60-65. Retrieved from http://www2.ncte.org/resources/journals/english-journal/

Hytner, N. (2013). Othello by William Shakespeare. National Theater, London.

McGlinn, J. E., \& McGlinn, J. M. (2003). Motivating learning in a humanities class through innovative research assignments: A case study. Retrieved from https://files.eric.ed.gov/fulltext/ED479392.pdf

Milam, W. (2007). Othello by William Shakespeare.

Reynolds, C., Stevens, D. D., \& West, E. (2013). "I'm in a professional school! Why are you making me do this?" A cross-disciplinary study of the use of creative classroom projects on student learning. College Teaching, 61(2), 51-59.

Shoemaker, B. (2013). To read or not to read: Five approaches to teaching Shakespeare. English Journal, 102(4), 111-114. Retrieved from http://www2.ncte.org/resources/ journals/english-journal/

Wilson, P. (2011). Creative writing and critical response in the university literature class. Innovations in Education and Teaching International, 48(4), 439-446. 